\title{
Comparison of Flavonoids from Spina Gleditsiae by Response Surface Method and Orthogonal Design
}

\author{
Xiaojuan Liu ${ }^{1, *}$, and Zhong $\mathrm{Li}^{2}$ \\ ${ }^{1}$ Jiangsu Provincial Xuzhou Pharmaceutical Vocational College, Xuzhou, China \\ ${ }^{2}$ College of Life Sciences, Tarim Univerrsity, Alaer, China
}

\begin{abstract}
In this paper, the effects of extraction temperature, extraction pressure and dosage of entrainer on flavonoids yield were studied. The optimal process determined by response surface method was extraction temperature as $48.52^{\circ} \mathrm{C}$, extraction pressure as $40 \mathrm{MPa}$, dosage of entrainer as $36.13 \mathrm{~mL}$, theoretical predictive yield as $0.791 \%$, actual verified yield as $0.793 \%$, and there was an interaction between the extraction temperature and dosage of entrainer. The optimum process determined by orthogonal design was extraction temperature as $50^{\circ} \mathrm{C}$, extraction pressure as $40 \mathrm{MPa}$, dosage of entrainer as $37.5 \mathrm{~mL}$, and actual verified yield as $0.779 \%$. Although the two methods obtained similar best processes, the response surface method could provide more accurate information, and the final flavonoids yield was also highest, which was worth promoting.
\end{abstract}

\section{Introduction}

Response surface method and orthogonal design are methods commonly used for experimental optimization at present. The two optimization methods have advantages and disadvantages in different applications, so it depends on the specific circumstances instead of being generalized.

In order to avoid blindly choosing optimization methods in the experiment, response surface method and orthogonal design were used to optimize the extraction of flavonoids from spina gleditsiae. In this study, the differences between two methods on the extraction were discussed, so as to provide reasonable guidance for the experimental optimization design.

\section{Materials and methods}

In this study, supercritical $\mathrm{CO}_{2}$ fluid extraction was used as the basic process for extraction of flavonoids from spina gleditsiae. A certain amount of 60-80 mesh spina gleditsiae particles was weighed and extracted in supercritical $\mathrm{CO}_{2}$ fluid extraction tank under different conditions. Flavonoids yield was determined by uv spectrophotometry.

\subsection{Single factor test}

Extraction of flavonoids from spina gleditsiae by supercritical $\mathrm{CO}_{2}$ fluid was worked at different extraction temperatures, extraction pressures, and dosage of entrainer ( $75 \%$ ethanol).

\subsection{Orthogonal experiment}

According to the single factor test results, three factorsthree levels of orthogonal test were designed. Three factors were extraction temperature (A), extraction pressure (B) and dosage of entrainer (C). Data were analysed by SPSS software.

\subsection{Response surface optimization test}

According to the single factor test results, the boxbehnken centre combination was used to design a three factor-three level response surface analysis test with extraction temperature (A), extraction pressure (B) and dosage of entrainer (C) as independent variables and flavonoids yield $(\%)$ as response value. The data was analysed by the design-expert software.

\section{Results and discussion}

\subsection{Single factor test results and analysis}

The effect of each single factor on flavonoids yield was shown in figure 1 . Selected the factors contained the highest yield for next tests, the extraction temperature as 30,40 and $50^{\circ} \mathrm{C}$, extraction pressure as 20,30 and 40 $\mathrm{MPa}$ and dosage of entrainer as 25, 37.5 and $50 \mathrm{~mL}$.

\footnotetext{
* Corresponding author: $\underline{\text { liuxj2000@ } 126 . c o m}$
} 

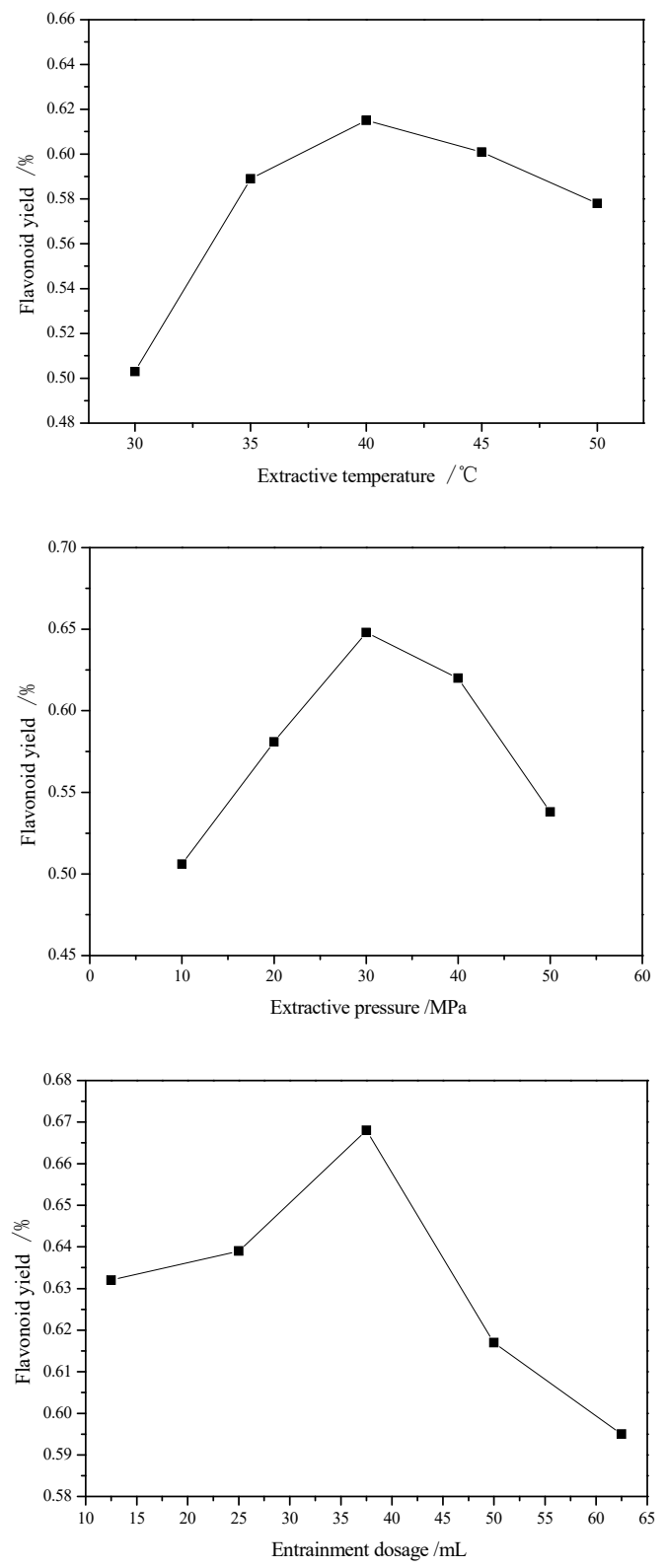

Figure 1. Effects of single factor on flavonoids yield.

\subsection{Response surface test design and results}

The response surface test design and results were shown in table 1 , with each test repeated twice.

Table 1. Box-Behnken design arrangement and corresponding experimental results for response surface analysis

\begin{tabular}{ccccccc}
\hline \multirow{2}{*}{ No. } & \multicolumn{3}{c}{ Factor } & \multicolumn{3}{c}{ Yield $(\%)$} \\
\cline { 2 - 7 } & A & B & C & 1 & 2 & Average \\
\hline 1 & 40 & 30 & 37.5 & 0.774 & 0.768 & 0.771 \\
2 & 50 & 40 & 37.5 & 0.780 & 0.778 & 0.779 \\
3 & 50 & 20 & 37.5 & 0.734 & 0.736 & 0.735 \\
4 & 50 & 30 & 50 & 0.757 & 0.757 & 0.757 \\
5 & 40 & 20 & 50 & 0.726 & 0.730 & 0.728 \\
6 & 30 & 20 & 37.5 & 0.707 & 0.708 & 0.707 \\
7 & 40 & 20 & 25 & 0.708 & 0.704 & 0.706 \\
8 & 40 & 40 & 25 & 0.751 & 0.747 & 0.749 \\
9 & 40 & 30 & 37.5 & 0.772 & 0.74 & 0.773 \\
10 & 30 & 30 & 50 & 0.729 & 0.729 & 0.729 \\
11 & 40 & 40 & 50 & 0.768 & 0.770 & 0.769 \\
12 & 40 & 30 & 37.5 & 0.775 & 0.773 & 0.774 \\
\hline
\end{tabular}

\begin{tabular}{ccccccc}
\hline 13 & 50 & 30 & 25 & 0.761 & 0.761 & 0.761 \\
14 & 40 & 30 & 37.5 & 0.771 & 0.767 & 0.769 \\
15 & 40 & 30 & 37.5 & 0.752 & 0.756 & 0.754 \\
16 & 30 & 30 & 25 & 0.641 & 0.641 & 0.641 \\
17 & 30 & 40 & 37.5 & 0.707 & 0.707 & 0.707 \\
\hline
\end{tabular}

Multiple regression fitting was performed on the experimental data with design expert software to obtain the quadratic regression equation with flavonoids yield as objective function:

$$
\begin{gathered}
Y=0.77 A++0.031 B+0.016 B+0.016 C+0.011 A B- \\
0.023 A B-0.001 B C-0.026 A^{2}-0.010 B^{2}-0.020 C^{2}
\end{gathered}
$$

The regression analysis results of the model were shown in table 2 .

Table 2. Analysis of variance for quadratic polynomial model.

\begin{tabular}{cccccc}
\hline Source & Sum of squares & df & Mean square & F value & P-value \\
\hline Model & 0.020 & 9 & $2.202 \times 10^{-3}$ & 15.80 & 0.0023 \\
$A$ & $0.008 \times 10^{-3}$ & 1 & $7.668 \times 10^{-3}$ & 55.18 & 0.0001 \\
$B$ & $0.002 \times 10^{-3}$ & 1 & $2.048 \times 10^{-3}$ & 14.70 & 0.0064 \\
$C$ & $0.002 \times 10^{-3}$ & 1 & $1.984 \times 10^{-3}$ & 14.24 & 0.0069 \\
$A B$ & $4.840 \times 10^{-4}$ & 1 & $4.840 \times 10^{-4}$ & 3.47 & 0.1046 \\
$A C$ & $2.116 \times 10^{-3}$ & 1 & $2.116 \times 10^{-3}$ & 15.19 & 0.0059 \\
$B C$ & $1.000 \times 10^{-6}$ & 1 & $1.000 \times 10^{-6}$ & $7.177 \times 10^{-3}$ & 0.9349 \\
$A^{2}$ & $2.868 \times 10^{-3}$ & 1 & $2.868 \times 10^{-3}$ & 20.59 & 0.0027 \\
$B^{2}$ & $4.295 \times 10^{-4}$ & 1 & $4.295 \times 10^{-4}$ & 3.08 & 0.1226 \\
$C^{2}$ & $1.701 \times 10^{-3}$ & 1 & $1.701 \times 10^{-3}$ & 12.21 & 0.0101 \\
Residual & $9.753 \times 10^{-4}$ & 7 & $1.393 \times 10^{-4}$ & & \\
Lack of & $7.085 \times 10^{-4}$ & 3 & $2.362 \times 10^{-4}$ & 3.54 & 0.1268 \\
Fit & & & & & \\
Pure & $2.668 \times 10^{-4}$ & 4 & $6.670 \times 10^{-5}$ & & \\
Error & & & & & \\
Cor Total & 0.021 & 16 & & & \\
\hline
\end{tabular}

As shown in table 2, $\mathrm{F}=15.80, \mathrm{P}=0.0023<0.01$, indicated that the regression of the model was very significant. Lack of fit $\mathrm{P}=0.1268>0.05$, indicated which was not significant. The linear relationship between the dependent variable and the investigated variables was significant, and the model adjusted determination coefficient $\mathrm{R}^{2}$ Adj $=0.8928$, indicating that the model could explain the change of response value of $89.28 \%$. The results showed that the model was fit well and the error was small, which could be used to predict the best extraction process of flavonoids from spina gleditsiae.

As could be seen from table $2, \mathrm{P}$ values of $\mathrm{A}, \mathrm{B}, \mathrm{C}$, $\mathrm{AC}, \mathrm{A}^{2}$ and $\mathrm{C}^{2}$ were less than 0.05 which indicated significantly different, and the $\mathrm{F}$ value of each factor was $\mathrm{FA}>\mathrm{FB}>\mathrm{FC}$, indicating that the extraction temperature, extraction pressure and entrainer dosage had significant effects on flavonoids yield. There were interaction effects, which could also be verified according to the three-dimensional response surface.

The response surface trend of extraction temperature and entrainer dosage was parabola with maximum value and maximum curved degree, indicating the strongest interaction between $\mathrm{AC}$, as shown in figure $2 \mathrm{~b}$. In figure $2 \mathrm{a}$ and $2 \mathrm{c}$, the curved surfaces were gentle and the contour lines were close to a normal circle, indicating that the interactions of $\mathrm{AB}$ and $\mathrm{BC}$ were weak. 

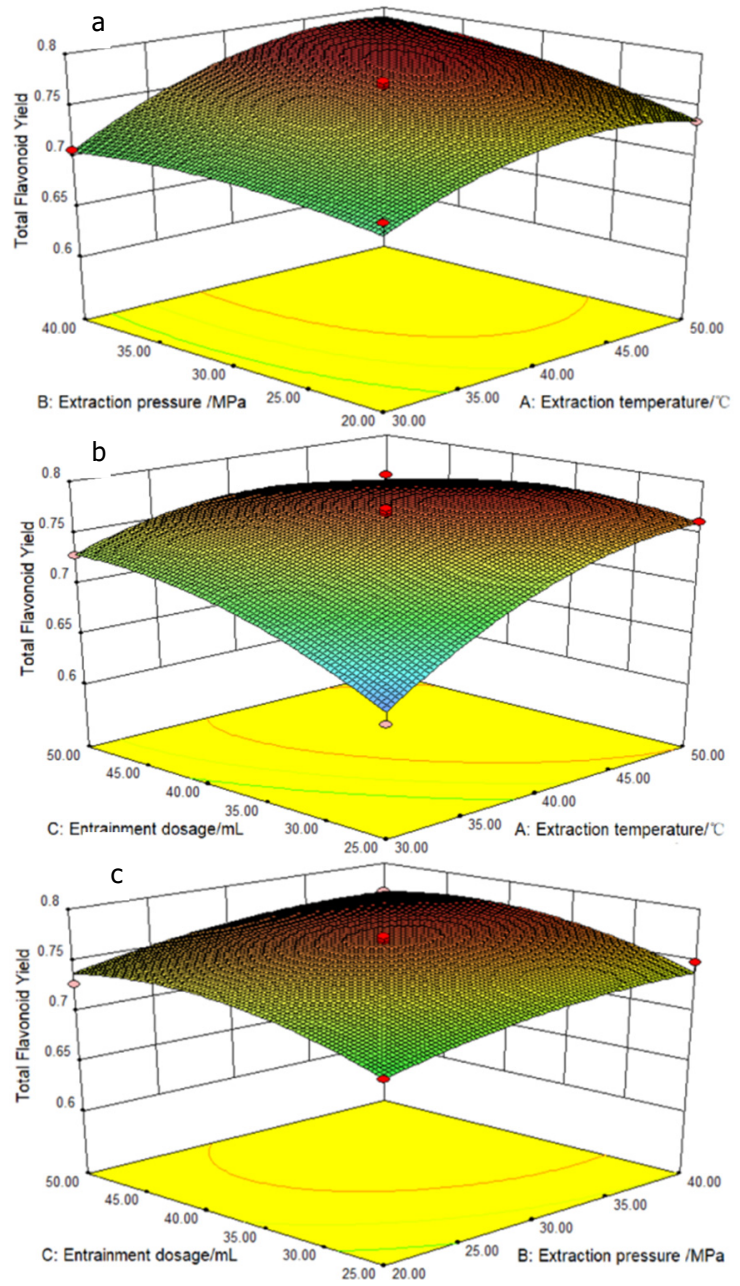

Figure 2. Response surface diagram of flavonoids yield.

According to the model, theoretical value of flavonoids extraction optimum process were as follows: extraction temperature as $48.52^{\circ} \mathrm{C}$, extraction pressure as $40 \mathrm{MPa}$, dosage of entrainer as $36.13 \mathrm{~mL}$, theoretical predictive yield as $0.791 \%$, actual verified yield as $0.793 \%$. After three parallel tests, the actual flavonoids yield was $0.793 \%$, which was slightly higher than the model prediction. It was shown that the equation was well fitted to the actual situation and the correctness of the model was fully verified.

\subsection{Orthogonal test design and results}

Orthogonal test was conducted according to the single factor test results, as shown in table 3 .

Table 3. Design and results of orthogonal design.

\begin{tabular}{ccccccc}
\hline \multirow{2}{*}{ No. } & \multicolumn{3}{c}{ Factor } & \multicolumn{4}{c}{ Yield (\%) } \\
\cline { 2 - 7 } & A & B & C & 1 & 2 & Average \\
\hline $\mathbf{1}$ & 30 & 20 & 25 & 0.711 & 0.711 & 0.711 \\
$\mathbf{2}$ & 30 & 30 & 37.5 & 0.719 & 0.715 & 0.717 \\
$\mathbf{3}$ & 30 & 40 & 50 & 0.722 & 0.724 & 0.723 \\
$\mathbf{4}$ & 40 & 20 & 37.5 & 0.743 & 0.743 & 0.743 \\
$\mathbf{5}$ & 40 & 30 & 50 & 0.747 & 0.750 & 0.749 \\
$\mathbf{6}$ & 40 & 40 & 25 & 0.752 & 0.753 & 0.753 \\
$\mathbf{7}$ & 50 & 20 & 50 & 0.759 & 0.759 & 0.759 \\
$\mathbf{8}$ & 50 & 30 & 25 & 0.762 & 0.759 & 0.761 \\
$\mathbf{9}$ & 50 & 40 & 37.5 & 0.778 & 0.779 & 0.779 \\
$\mathbf{K}_{\mathbf{1}}$ & 0.717 & 0.738 & 0.742 & & & \\
$\mathbf{K}_{\mathbf{2}}$ & 0.748 & 0.742 & 0.746 & & & \\
$\mathbf{K}_{\mathbf{3}}$ & 0.766 & 0.752 & 0.744 & & & \\
\hline
\end{tabular}

\begin{tabular}{|c|c|c|c|}
\hline \multirow{2}{*}{$\begin{array}{c}\text { Optimum } \\
\mathbf{R}\end{array}$} & \multicolumn{3}{|r|}{$\mathrm{A}_{3}>\mathrm{B}_{3}>\mathrm{C}_{2}$} \\
\hline & 0.049 & 0.014 & 0.004 \\
\hline Prioritize & & & $\mathrm{A}>\mathrm{B}>\mathrm{C}$ \\
\hline
\end{tabular}

Statistics analysis showed that the influence of various factors on the flavonoids yield was: $A_{3}>B_{3}>C_{2}$, which mean the best technology of flavonoids from spina gleditsiae was extraction temperature as $50^{\circ} \mathrm{C}$, extraction pressure as $40 \mathrm{MPa}$, dosage of entrainer as $37.5 \mathrm{~mL}$. It was found by variance analysis that the extraction temperature had significant influence on the test, while the extraction pressure and entrainer dosage had no significant influence, which was consistent with the response surface analysis results.

\subsection{Comparison of response surface method and orthogonal design}

Based on single factor analysis, response surface method and orthogonal design could explore the effect of extraction temperature, extraction pressure and entrainer dosage on flavonoids from spina gleditsiae, and obtained the best extraction process. However, both two methods had advantages and disadvantages.

Table 4. Comparison of verification tests.

\begin{tabular}{cccccc}
\hline Method & \multicolumn{3}{c}{ Factor } & Predictive & $\begin{array}{c}\text { Real } \\
\text { Yield\% }\end{array}$ \\
\cline { 2 - 4 } Yield \% \\
\hline $\begin{array}{c}\text { Response } \\
\text { Surface Method }\end{array}$ & 48.52 & 40 & 36.13 & 0.791 & 0.793 \\
$\begin{array}{c}\text { Orthogonal } \\
\text { Design }\end{array}$ & 50 & 40 & 37.5 & - & 0.779 \\
\hline
\end{tabular}

The response surface method designed the three factor three level tests for 17 groups (Table 1), in which there were 5 groups of repeated centre points, and each test was repeated for at least 2 times, so there were at least 29 tests. The orthogonal design was performed in 9 groups (Table 3), with each group repeating at least 2 times, and the experiment was conducted at least 18 times. The optimal process results obtained by the two methods were basically the same as shown in table 4 .

The results of variance analysis showed that the extraction temperature had significant effect on flavonoids yield, while the extraction pressure and dosage of entrainer had little effect. However, the response surface method could analyse could not only know the significant effect of each factor on the extraction rate, but also further analysed the interaction between factors (Table 2 and Figure 2). The existing orthogonal experimental data could not judge whether there was interaction between factors.

The response surface method could simulate the optimal process intuitively and accurately with designexpert software, and the predicted value could be given, while the orthogonal method only selected the factor value that had already occurred, and could not predict the result. The results showed that the actual value of response surface method was $0.002 \%$ higher than the predicted value, and $0.022 \%$ higher than the orthogonal method. 


\section{Conclusions}

Response surface method and orthogonal design could be used to analyse and optimize the supercritical extraction process of flavonoids from spina gleditsiae. However, the response surface method could provide more accurate data information in the case of a small increase of the number of tests, which was more conducive to finding the best process in production practice, saving cost, and could also simulate and predict the highest yield, which was worthy of promotion. The best extraction process for flavonoids was extraction temperature as $48.52^{\circ} \mathrm{C}$, extraction pressure as $40 \mathrm{MPa}$, dosage of entrainer as $36.13 \mathrm{~mL}$, and flavonoids yield as $0.793 \%$. The extraction temperature had a significant effect on flavonoids from spina gleditsiae and had an interaction with entrainer dosage.

\section{Acknowledgments}

This work was financially sponsored by Qing Lan Project of Jiangsu Province (2017), Basic Research for Application Projects (KH17022) of Xuzhou, and Natural Science Research Projects of Xuzhou Pharmaceutical Vocational College.

\section{References}

1. Liu Wei, Yu Yanying, Yang Ruzhen, International journal of molecular sciences, 11(2010)

2. Steadman K J, Burgoon M S, Lewis B A, Journal of The Science of Food And Agriculture, 81(2001)

3. Mongkholkhajornsilp D, Douglas S, Journal of Food Engineering, 71(2006)

4. Özkal S G, Yener M E, Bayındırlı L, Journal of Supercritical Fluids, 35(2005)

5. Wang Q, Guan YX, Yao SJ, Chemical Engineering Journal, 159(2010)

6. Wang Q, Guan YX, Yao SJ, The Journal of Supercritical Fluids, 56(2011)

7. Adami R, Osséo LS, Reverchon E, Biotechnology and Bioengineering, 104(2009) 